\title{
Schwartz-Jampel syndrome in two daughters of first cousins
}

\author{
LORENZO PAVONE, FLORINDO MOLLICA, A NGELO GRASSO, \\ A NTO N I O C A O, A ND F I L I P P G U L L O T T A \\ From the Departments of Pediatrics and Neurology, University of Catania, the Department of \\ Pediatrics, University of Cagliari, Italy, and the Department of Neuropathology, University of Bonn, \\ Germany
}

SUMMARY The clinical and pathological features of two sisters born from consanguineous parents and affected by the rare Schwartz-Jampel syndrome are reported. The parental consanguinity of these two patients and the findings of electromyographic changes in the mother strongly support an autosomal recessive pattern of inheritance. No response of growth hormone secretion to arginine and insulin stimulation tests was found.

Schwartz-Jampel syndrome, also known as osteochondromuscular dystrophy, chondrodystrophic myotonia, or dysostosis enchondralis metaepiphysaria of the Catel-Hempel type, is characterised by a typical facies, muscle and skeletal abnormalities, and growth retardation. Autosomal recessive inheritance has been suggested for this disease.

Twenty patients with the syndrome have been described (Catel, 1951; Schwartz and Jampel, 1962; Aberfeld et al., 1965; Huttenlocher et al., 1969; Mereu et al., 1969; Saadat et al., 1972; Taylor et al., 1972; Beighton, 1973; CordeiroFerreira et al., 1973; Fowler et al., 1974; Van Huffelen et al., 1974; Greze et al., 1975; Horan and Beighton, 1975; Kirschner and Pachman, 1976).

The present paper describes an additional family with two sisters born from consanguineous parents and affected by this rare syndrome. In these patients there was no response of the growth hormone secretion to arginine and insulin stimulation tests.

\section{Case reports}

Figure 1 shows the pedigree of the $P$ family who come from a small village in eastern Sicily. The parents of our probands are first cousins (degree of consanguinity $1: 16$ ) and apparently healthy;

Address for reprint requests: Professor L. Pavone, Department of Pediatrics, University of Catania, Viale Andrea Doria, Catania, Italy. Accepted 26 September 1977 they are 41 and 34 years old respectively. Two maternal uncles of the probands, III, 12 and III, 13, who were male twins born at term, died of unknown causes in the second and third days of life respectively. Other family data are irrelevant.

The first and third pregnancy of III, 9 gave birth to two normal children who are in good health. The second pregnancy ended in spontaneous abortion during the second month of gestation.

\section{CASE 1}

LP (IV, 18 in Fig. 1) was born at term on 20 April 1969. There had been a threatened abortion during the second month of gestation. She was thought to be of normal size at birth but no weight was recorded. She had moderate asphyxia. Physical development was normal during the first year of life, except for a delay in dental eruption which began at 12 months. From the second year of life the parents noticed that the girl had an unusual position of the lips. Since then her facial appearance has become more and more peculiar, and contractures of several muscular groups have appeared. Progressive muscular weakness and walking difficulties started during the third year.

The girl was admitted to hospital on 9 February 1976 when she was nearly 7 years old (Fig. 2). She weighed $20.1 \mathrm{~kg}$ (below the 10th centile), and was $1100 \mathrm{~mm}$ tall (below the 3rd centile). Her face was triangular, with a small, sharp-pointed, receding chin. The forehead was narrow, with low set hair. The eyebrows were widely spaced and the nose root was large and prominent. There was 

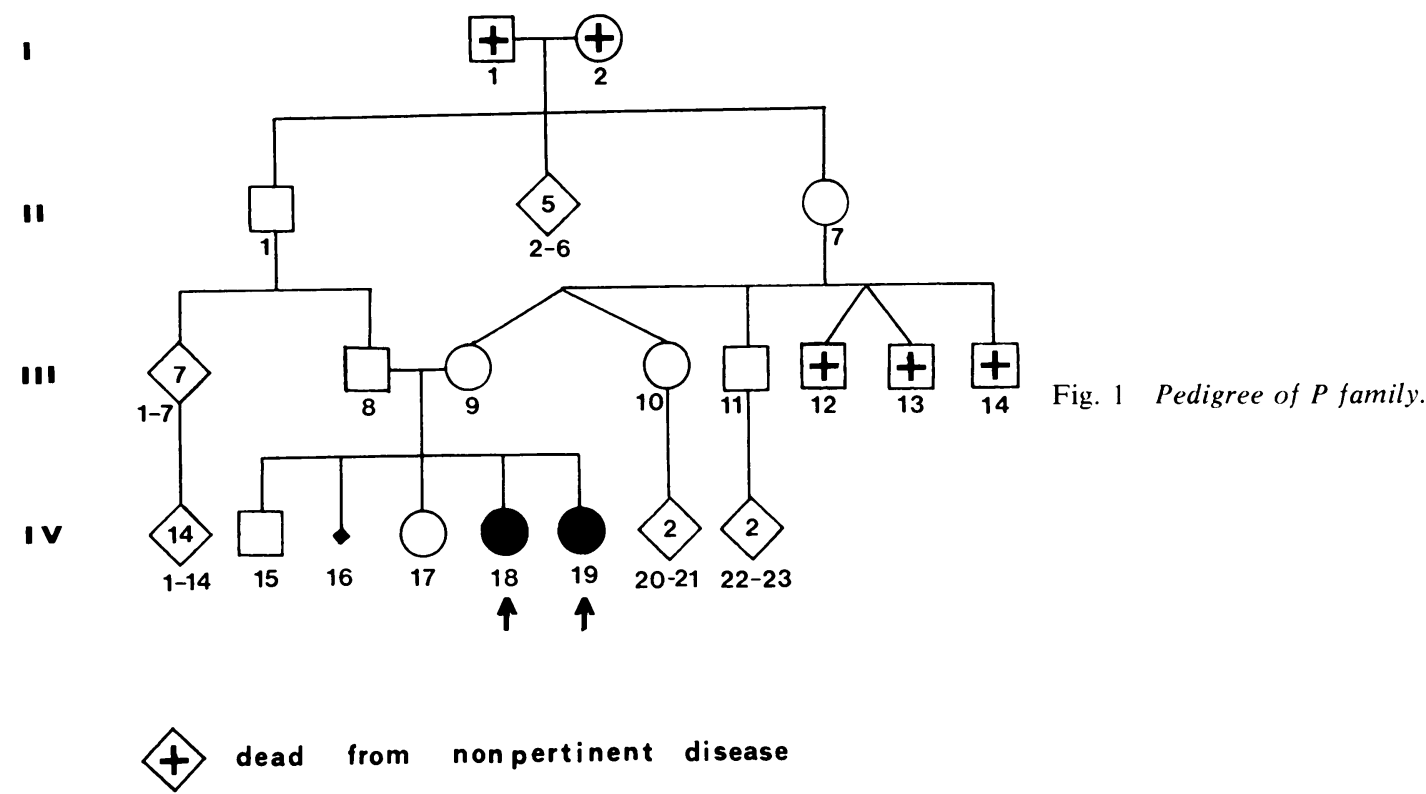

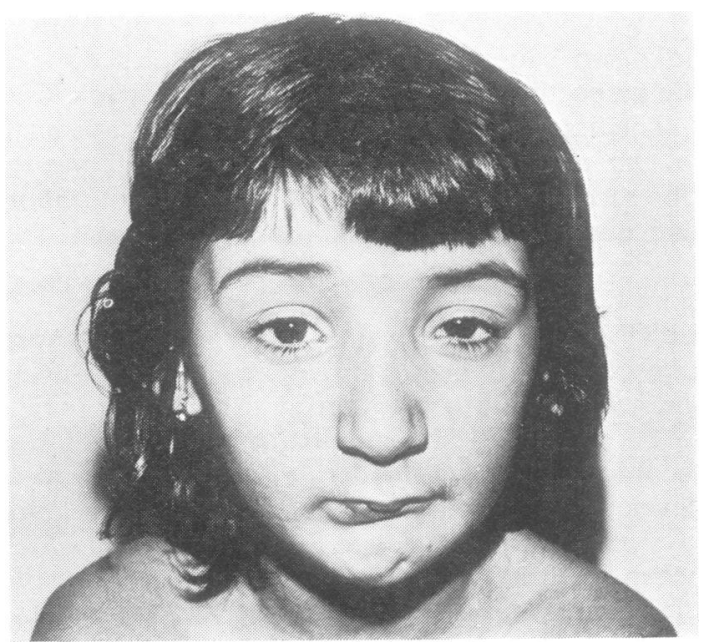

Fig. 2 Case 1 Loredana $P$.

slight ptosis. The palpebral fissures were short and moderately narrowed. The mouth was small and pursed. The upper lip was relatively long and protruding, the lower lip short and contracted, with a deep horizontal furrow immediately below the mucosal margin. The thoracic cage was thin, with mild pigeon breast deformity and everted costal margins. The voice was nasal and high-pitched. There was severe myopia. Contractures of several muscular groups were present, particularly of the facial muscles and of suprascapularis, subscapularis, rhomboides, and dentatus. Percussion of these muscles did not evoke any clinically evident myotonic response, probably because the muscles were continuously and unceasingly contracted. Even the muscles of the legs were contracted, and there was slight equinovarus deformity of the feet. Because of the contractures, passive movements met resistance and were limited in their extreme degree. The muscles were firm to palpation. The gait was laborious and stiff. There was moderate kyphoscoliosis. Tendon reflexes and muscular strength, while difficult to evaluate, appeared normal. Intelligence was impaired (IQ 80).

The electromyogram showed no electric silence at rest but a continuous incessant spontaneous activity, with frequent bursts (Fig. 3) after voluntary contraction, needle movements, and particularly spontaneously, accompanied by a "dive bomber" sound. An electroencephalogram was normal. Ophthalmological examination showed myopic staphylomas of the sclerae associated with myopia of 8-10 diopters bilaterally; there was no corneal clouding.

An intracutaneous PPD tuberculin test was positive, although the girl had not been vaccinated against tuberculosis and there was no history of tubercular disease. Urine analysis, blood cell count, blood urea nitrogen, and blood glucose levels were normal. Serum calcium was 1.9 $\mathrm{mmol} / \mathrm{l}(7.6 \mathrm{mg} / \mathrm{dl})$, phosphate $1.5 \mathrm{mmol} / 1(4.7$ 


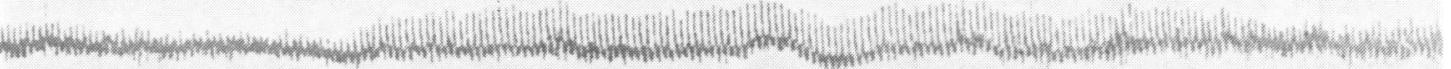

Fig. 3 Electromyogram showing continuous activity at rest and apparently spontaneous burst of increased activity (case 1).

$\mathrm{mg} / \mathrm{dl}$ ), proteins $85.6 \mathrm{~g} / \mathrm{l}$ with diminished albumin/ globulin ratio $(0.66)$ and moderate increase of gammaglobulins $(24 \%)$. Serum immunoglobulins were within normal levels in two determinations: $\operatorname{IgG}(1.5 \mathrm{~g} / 1$ twice $), \operatorname{IgA}(1.91$ and $1.84 \mathrm{~g} / \mathrm{l}), \operatorname{IgM}$ (3.46 and $3.07 \mathrm{~g} / \mathrm{l})$, and $\operatorname{IgE}(0.38$ and $0.33 \mathrm{~g} / \mathrm{l})$. $\mathrm{C}^{\prime} 3$ was also normal $(0.64$ and $0.66 \mathrm{~g} / 1)$. Normal values of serum creatinephosphokinase, aldolase, glutamic oxalacetic, and glutamic pyruvic transaminase were also obtained. Serum and urine aminoacids and karyotype were normal, as well as urine studies for mucopolysaccharides. Radiographic studies revealed only mild generalised osteoporosis, a cone-shaped appearance of the chest with caudally projecting ribs, and moderate bilateral coxa valga. The skeletal age was normal.

Growth hormone secretion was studied by stimulation with arginine $(0.5 \mathrm{~g} / \mathrm{kg})$ and insulin $(0.1 \mathrm{U} / \mathrm{kg}$ iv). Despite a marked fall in blood glucose level, the growth hormone, determined at 30 minute intervals for 120 minutes, never exceeded the basal value of $3 \mathrm{ng} / \mathrm{ml}$.

\section{CASE 2}

SP (IV, 19 in Fig. 1) was born at term on 5 July 1970 after a normal pregnancy and delivery. Birth weight was normal, and the neonatal period uneventful. The infant developed normally during the first two years of life. By the end of the second year a modification of the face similar to that of her older sister became evident. By the age of $2 \frac{1}{2}$ years the gait became difficult, and progressive loss of muscular strength occurred.

On admission to hospital this $5 \frac{1}{2}$ year old girl weighed $18.4 \mathrm{~kg}$ (below the 25th centile), and was $1030 \mathrm{~mm}$ tall (below the 3 rd centile). Even at rest and when secretly observed, she maintained a position like a person posing for a "physique shot" for the camera. Her aspect was very similar to that of her sister (Fig. 4), particularly in the widely spaced eyebrows, prominent nasal root, moderately narrowed palpebral fissures, contracted and small mouth, and sharp pointed chin. The neck was short and the thorax restricted, particularly in its transverse diameter. The voice was nasal and high pitched.

There were contractures of several muscle groups: this was particularly evident in the back,

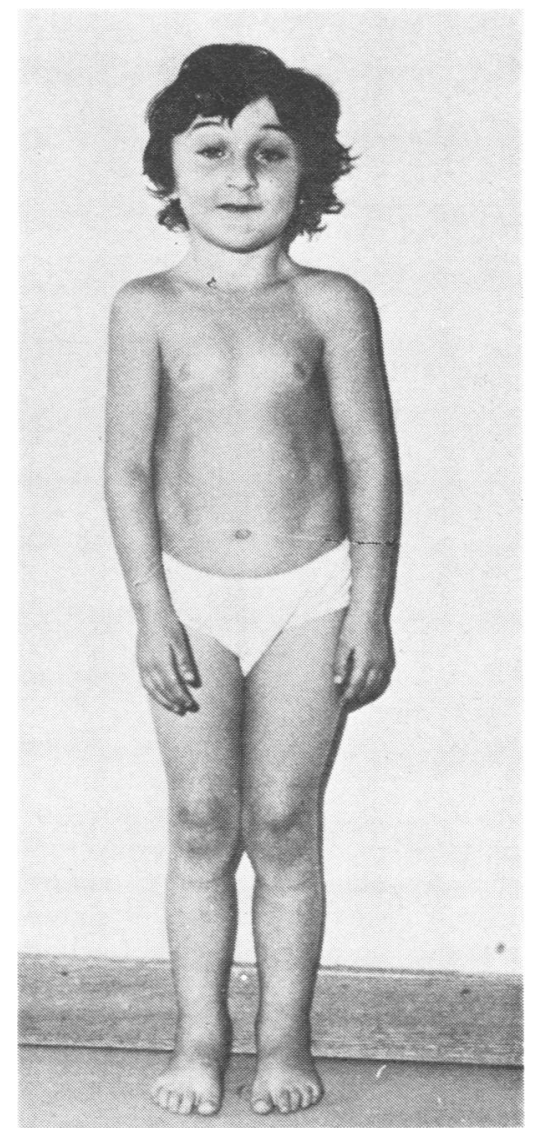

Fig. 4 Case 2 Sabina $P$. 
where, because of the contractures of trapezium, suprascapularis, and subscapularis there was a deep dimple immediately below the spine of the scapula bilaterally (Fig. 5). The consistence of the muscular masses was increased and active and passive movements were limited. There was mild kyphoscoliosis. The gait was moderately hampered because of muscular hyperactivity. The tendon reflexes were normal. There was a mild but definite degree of mental deficiency, with an IQ of 70 .

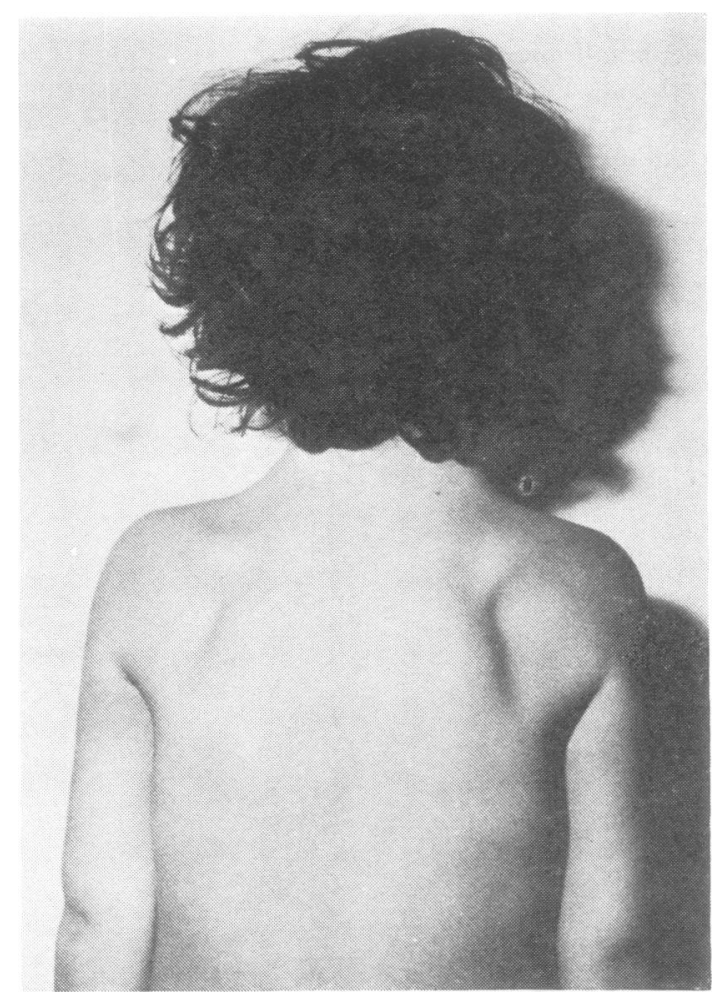

Fig. 5 Severe contractures of the back muscles (case 2). Note dimples below the spines of the scapulae.

Percussion of muscles did not elicit myotonic response which was clinically visible but the electromyogram was clearly myotonic: it showed no silence at rest, and there were bursts of activity both spontaneously and provoked by voluntary contraction, muscle percussion, and movement of the needle. The electroencephalogram and karyotype were normal. An ophthalmological examination failed to show any abnormalities.

The following laboratory data were within nor- mal limits: blood cell count, urine analysis, blood urea nitrogen, blood glucose, calcium, phosphate, proteins, serum and urine aminoacid chromatography, serum immunoglobulins IgG, IgA, IgM, $\mathrm{IgE}$, and the $\mathrm{C}^{\prime} 3$ fraction of complement, and urine mucopolysaccharides.

Even the serum enzymes creatinephosphokinase, aldolase, glutamic oxalacetic and glutamic pyruvic transaminases were normal. Radiological examination of the skeleton was also normal. An intravenous infusion of arginine $(0.5 \mathrm{~g} / \mathrm{kg})$ and insulin $(0.1 \mathrm{U} / \mathrm{kg})$ produced after 30 minutes marked hypoglycaemia without increase of the serum growth hormone above the basal level of $3 \mathrm{ng} / \mathrm{ml}$. A fragment of deltoid muscle obtained by biopsy was examined by light and by electron microscope. In semithin sections some angulated hypotrophic fibres were present. The nerves appeared intact (Fig. 6).

By the electron microscope some muscle fibres showed a fine vacuolation due to a sacculated dilatation of the sarcoplasmic reticulum (Fig. 7). Triads were prominent, but did not show any alterations. Mitochondria appeared enlarged, their cristae were swollen; they were often densely응 packed, juxtanuclear, and beneath the sarcolemma

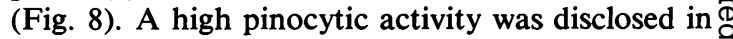
vascular endothelia, in sarcolemma and ing Schwann cells. Nerves did not show any alterations.

\section{FAMILY STUDY}

The mother was clinically normal. She had normal serum enzymes and immunoglobulin levels. An electromyogram showed abnormalities similar to those of the daughters but less pronounced (Fig. 9)

The father and the older sibs IV 15 and IV 17 (Fig. 1) were not available for the study.

\section{Discussion}

The cases reported here showed all the distinctive features of the Schwartz-Jampel syndrome which may be summarised as follows: (1) growth retardation; (2) typical facies; (3) myotonia; (4) skeletal deformities caused by osteochondrodystrophy. The main feature of the 22 known cases (including our own) are summarised in the Table. Apart from some bone deformities sometimes present at birth, the symptoms and signs usually appear only at the end of the first year or during the second year of life (Aberfeld, 1973): thereafter the disease shows a stationary or slowly progressive course.

There are 15 affected families from four conti- 

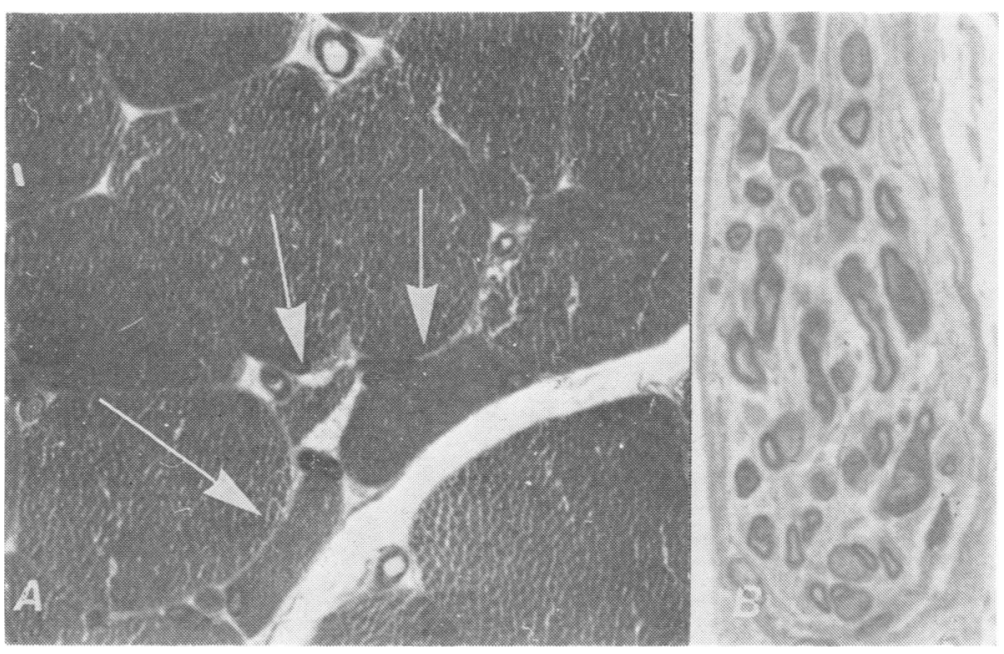

Fig. 6 Semithin sectionaraldite, methylene-blue (case 2) $A$ : three angulated hypotrophic fibres. $\times 160$. B: this intramuscular nerve shows no abnormality. $\times 200$.

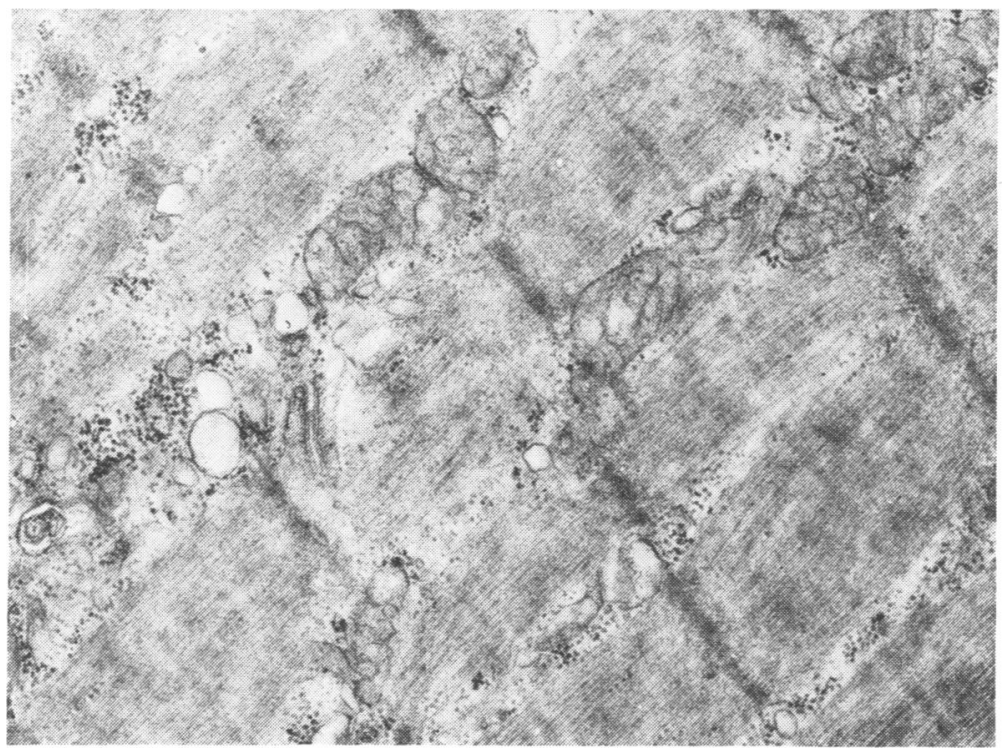

Fig. 7 Fine dilatation of sarcoplasmic reticulum (case 2). Mitochondria are swollen. Zeiss EM 10. $\times 20000$.

nents: six families are American, seven are European, and there is one family from South Africa and one from the middle East. Two of these 15 families have been reported twice independently (Schwartz and Jampel, 1962, Aberfeld et al., 1965; Mereu et al., 1969, Aberfeld et al., 1970). Our patients represent the seventh pair of affected sibs; there are two other pairs of affected sisters (Catel, 1951; Greze et al., 1975), one pair of affected brothers (Beighton, 1973), and three male-female pairs (Schwartz and Jampel, 1962; Huttenlocher et al., 1969; Mereu et al., 1969). Parental consan- guinity is present in this family and in three of the other 14 families (Saadat et al., 1972; Beighton, 1973; Greze et al., 1975). This high incidence is expected in connection with a very rare autosomal recessive disease.

Excluding the three families for which the number of unaffected sibs is unknown (Huttenlocher et al., 1969; Cordeiro-Ferreira et al., 1973; Kirschner and Pachman 1976), in the other 12 families there are 19 or 20 affected (a male sib of the patients described by Beighton was stillborn, and had bent limbs and an abnormal facies), and 

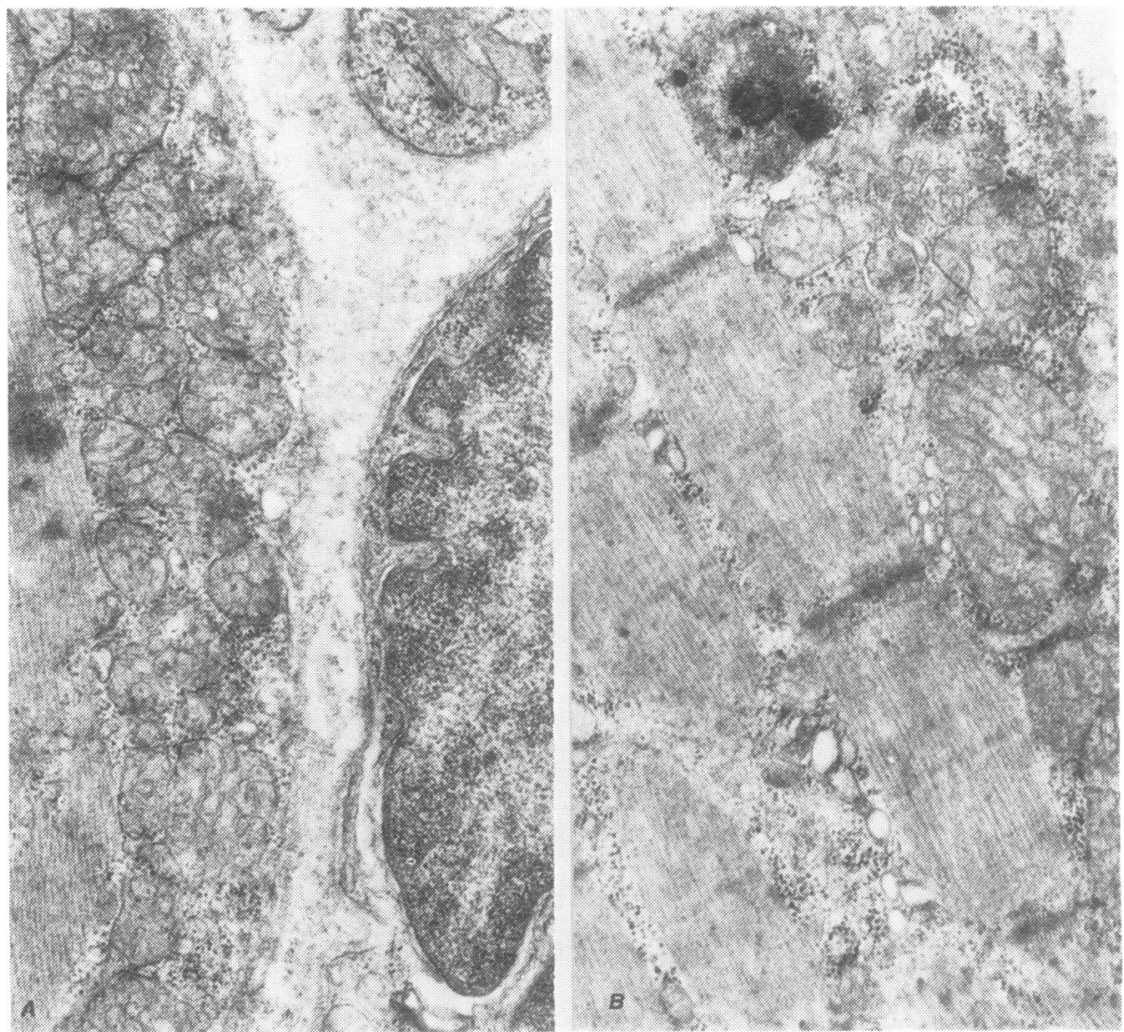

Fig. 8 A: clusters of swollen mitochondria beneath the sarcolemma. B: among densely-packed and swollen mitochondria some lipofuscin body is present.

Dilatation of sarcotubular system. Zeiss EM 10. $\times 20000$.



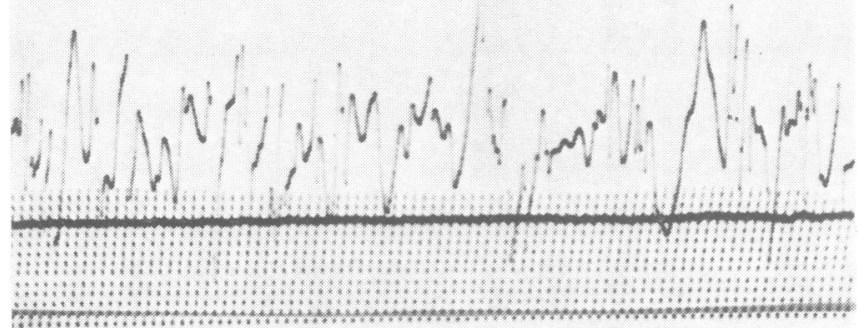

Fig. 9 Electromyogram of the mother of cases 1 and 2.

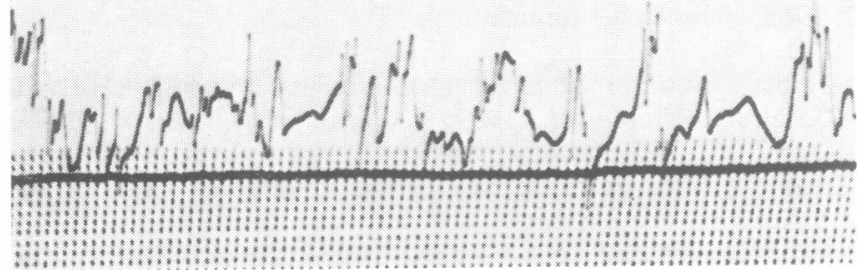




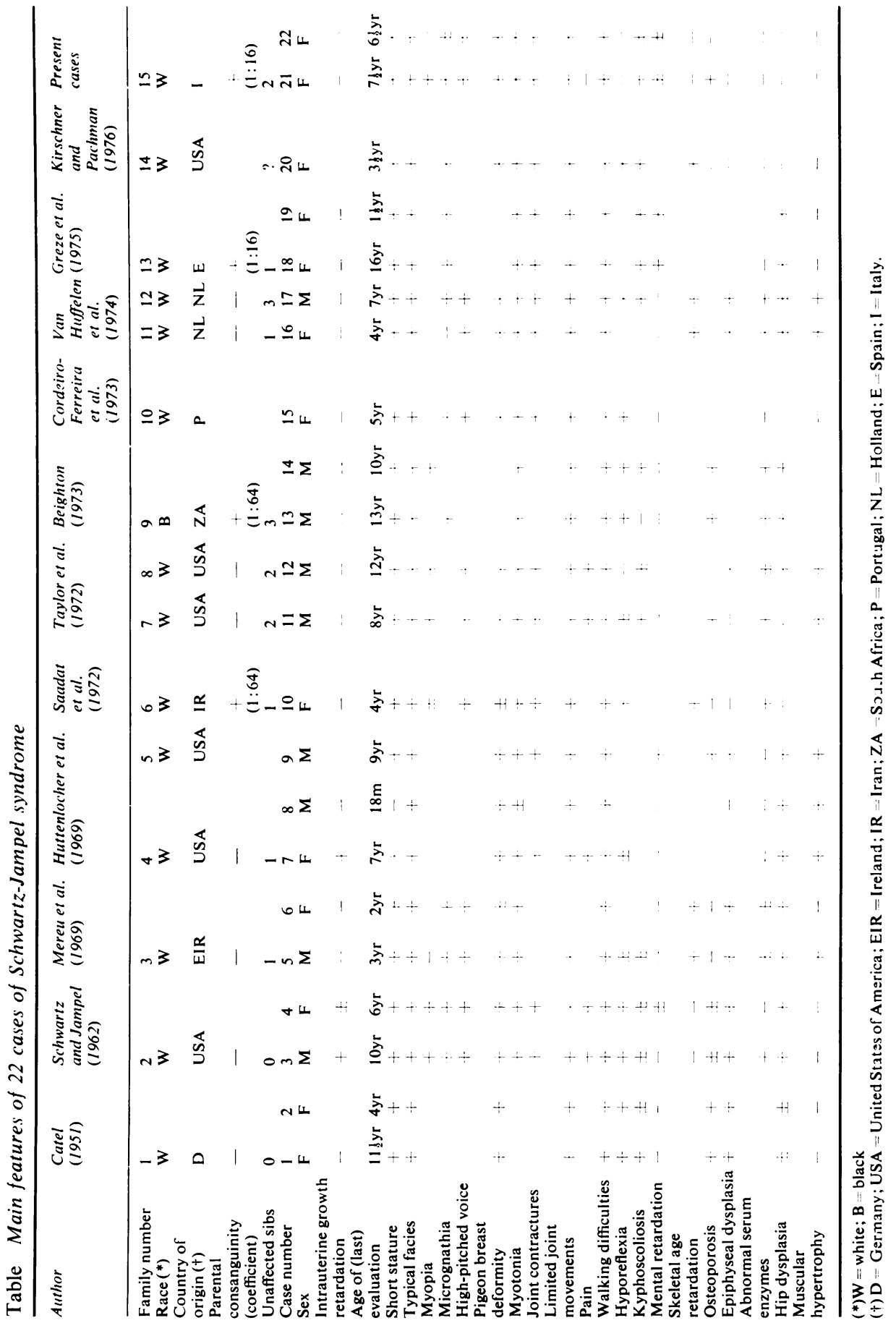


16 or 17 unaffected sibs; this is also an acceptable ratio for a recessive disease in which the selection of affected families has been made starting from the patients.

McKusick (1975) includes the Schwartz-Jampel syndrome among the diseases for which an autosomal recessive pattern of inheritance is considered quite certain. The parental consanguinity of our family, and the finding of electromyographic changes in the mother are additional strong arguments to support this interpretation. Van Huffelen et al. (1974) also found electromyographic abnormalities in several relatives of their two patients.

Unlike the patient described by Kirschner and Pachman (1976) who was prone to infections and in whom IgA deficiency was found, our patients did not show biological signs of immunological deficiency, even though the oldest sister showed a positive reaction to tuberculin.

The way in which the abnormal gene of the Schwartz-Jampel syndrome produces its adverse effect on physical growth is unknown. With three exceptions (Table, cases 3, 4, and 7) the growth retardation appeared only during extrauterine life. It is sometimes associated with significant degrees of skeletal age retardation (Table, cases 5, 6, 10, 16,17 , and 20), but thyroid function studies are always normal. Growth hormone secretion has been studied in four cases (Table, cases 3 to 6): in three cases it was found to be normal, and it was questionable in case 5 who was studied independently twice with different results: the first time an intravenous infusion of L-arginine monohydrochloride failed to produce a significant increase of growth hormone (Mereu et al., 1969), while the second time a serum assay for growth hormone by immunoelectrophoresis was normal (Aberfeld et al., 1970). In both our patients the intravenous infusion of arginine and insulin, although followed by marked hypoglycaemia, did not produce increase of serum growth hormone levels within two hours. The short stature of our patients could be attributed to deficiency of this hormone, even if the abnormal shape of the bones which is not seen in other varieties of growth hormone deficiency, is against this hypothesis.

The ultrastructural investigation of muscle showed clusters of enlarged mitochondria and swelling of sarcoplasmic reticulum, giving the impression of a fine vacuolation of muscle fibres. These findings have already been reported (Aberfeld et al., 1970; Fowler et al., 1974; Van Huffelen et al., 1974). However we saw neither the "streaming" of Z-lines reported by Van Huffelen et al. (1974) nor the dense homogeneous material described in the terminal cisternae of sarcoplasmic reticulum by Fowler et al. (1974).

The ultrastructural findings hitherto reported in Schwartz-Jampel syndrome are not characteristic. Swelling of the sarcotubular system, however, has been observed in those myopathies characterised by an alteration of muscle contraction-for example, periodic paralysis and dystrophia myotonica. In the latter also some hypotrophic angulated fibres (as seen in the present cases) are often observed (Gullotta, unpublished).

\section{References}

Aberfeld, D. C. (1973). Schwartz-Jampel syndrome. In Birth Defects, Atlas and Compendium. By D. Bergsma, pp. 798-799. Williams and Wilkins: Baltimore.

Aberfeld, D. C., Hinterbuchner, L. P., and Schneider, M. (1965). Myotonia, dwarfism, diffuse bone disease and unusual ocular and facial abnormalities (a new syndrome). Brain, 88, 313-322.

Aberfeld, D. C., Namba, T., Vye, M. V., and Grob, D. (1970). Chondrodystrophic myotonia: report of two cases. Myotonia, dwarfism, diffuse bone disease, and unusual ocular and facial abnormalities. Archives of Neurology (Chicago), 22, 455-462.

Beighton, P. (1973). The Schwartz syndrome in Southern Africa. Clinical Genetics, 4, 548-555.

Catel, W. (1951). Differentialdiagnostische Symptomatologie von Krankheiten des Kindesalters, pp. 48-52. George Thieme: Stuttgart.

Cordeiro-Ferreira, N., Gomes Da Costa, M. G., and Marques, D. (1973). Syndrome de Schwartz. Archives Françaises de Pédiatrie, 30, 208-209.

Fowler, W. M., Layzer, R. B., Taylor, R. G., Eberle, E. D., Sims, G. E., Munsat, T. L., Phillipart, M., and Wilson, B. W. (1974). The Schwartz Jampel syndrome. Its clinical physiological and histological expressions. Journal of the Neurological Sciences, 22, 127-146.

Greze, J., Baldet, P., Dumas, R., Cadilhac, J., Pages, A., and Jean, R. (1975). Dystrophie osteo-chondromusculaire de Schwartz-Jampel. Deux cas familiaux. Archives Françaises de Pédiatrie, 32, 59-75.

Horan, F., and Beighton, P. (1975). Orthopaedic aspects of the Schwartz syndrome. Journal of Bone and Joint Surgery, 57A, 542-544.

Huttenlocher, P. R., Landwirth, J., Hanson, V., Gallagher, B. B., and Bensch, K. (1969). Osteo-chondromuscular dystrophy. A disorder manifested by multiple skeletal deformities, myotonia, and dystrophic changes in muscle. Pediatrics, 44, 945-958.

Kirschner, B. S., and Pachman, L. M. (1976). IgA deficiency and recurrent pneumonia in the SchwartzJampel syndrome. Journal of Pediatrics, 88, 10601061.

McKusick, V. A. (1975). Mendelian Inheritance in Man. Fourth edition, p. 517. Johns Hopkins University Press: Baltimore and London. 
Mereu. T., Porter, I. H., and Hug, G. (1969). Myotonia, shortness of stature, and hip dysplasia. Schwartz-Jampel syndrome. American Journal of Disease of Children, 117, 470-478.

Saadat, M., Mokfi, H., Vakil, H., and Ziai, M. (1972). Schwartz syndrome: myotonia with blepharophimosis and limitation of joints. Journal of Pediatrics, 81, 348-350.

Schwartz, O., and Jampel, R. S. (1962). Congenital blepharophimosis associated with a unique generalised myopathy. Archives of Ophthalmology, 68, 5257.
Taylor, R. G., Lazer, R. B., Davis, H. S., and Fowler, W. M. (1972). Continuous muscle fiber activity in the Schwartz-Jampel syndrome. Electroencephalography and Clinical Neurophysiology, 33, 497-509.

Van Huffelen, A. C., Gabreels. F. I. M., Van Luypen, V. D., Horst, J. S., Slooff, J. L., Stadhouders, A. M., and Korten, J. J. (1974). Chondrodystrophic myotonia. A report of two unrelated Dutch patients. Neuropädiatrie, 5, 71-90. 